\title{
Rheumatology education and management skills in general practice: a national study of trainees
}

Peter Lanyon, Daniel Pope, Peter Croft, in collaboration with the Primary Care Rheumatology Society

\begin{abstract}
Objective-To evaluate current rheumatology education and skills during vocational training in general practice.

Methods-A postal questionnaire survey was sent to all general practice trainees who were in United Kingdom training practices in June 1992. A second survey was made of general practice trainers in the UK.

Results-Questionnaires were returned by 1624 trainees, representing $70 \%$ of all trainees known to be in a training practice on 1 April 1992. Of the 1075 responders who were at the end of their trainee year, $35 \%$ had not received any tutorials on rheumatological topics with their trainer, and only $43 \%$ had experienced specific rheumatology teaching on local day release courses. Although $84 \%$ of these trainees had injected or aspirated the knee, fewer than $40 \%$ had acquired shoulder injection skills. Lack of experience was matched by low reported confidence. Trainees rated the amount of their rheumatology education as inadequate. Nine hundred trainers returned questionnaires-a response rate of $33 \%$. Their estimate of the amount of local training provided was similar to that among the trainees, but this sample of trainers reported a higher level of practical teaching than the trainees indicated they had received.
\end{abstract}

Conclusions-Rheumatology education during vocational training needs to be improved, particularly the component provided by trainers and local day release courses. This process might be facilitated by the development of a standard rheumatology curriculum which could be incorporated into all training schemes.

(Ann Rheum Dis 1995; 54: 735-739)

Rheumatic disorders are common and distressing, troublesome in the short term and the dominant cause of long term disability in the United Kingdom. ${ }^{1}$ They are mostly treated outside hospital, accounting for $10 \%$ of a general practitioner's workload. ${ }^{2-4}$ Do general practitioners (GPs) receive adequate training to meet this demand? Indirect evidence suggests they do not, ${ }^{5-8}$ though the question has not been dealt with systematically. The consequences may be delayed or missed diagnoses, ${ }^{7}$ and referral of conditions which could be treated in the community. ${ }^{8}$
Undergraduate rheumatology training, despite improvements stimulated by initiatives such as those of the Arthritis and Rheumatism Council, ${ }^{9}$ has not led to a demonstrably high awareness of locomotor disorders among junior medical staff. ${ }^{10}$ Although $93 \%$ of medical schools now have formal rheumatology teaching, only $22 \%$ examine clinical skills. ${ }^{11}$

Whilst deficiencies in undergraduate training will influence the competence of general practitioners, postgraduate education is likely to be even more crucial, whether as continuing medical education or in the three years of mandatory vocational training. The educational 'window' provided by vocational training is the time when many attitudes and management strategies for future practice are formed, and provides the ideal framework for development of rheumatology knowledge and skills. Whilst the general training content of this period has been documented, ${ }^{12}$ very little is known of its rheumatology component. An assessment of this would enable current practice and needs to be identified and future educational objectives and initiatives to be planned.

The aim of this study was to investigate the content of rheumatology education during vocational training.

\section{Methods}

There were two target populations: all general practice trainees identified as being in a UK training practice in June 1992, and all general practice principals who were accredited as trainers in June 1992. Information was collected by two postal questionnaires.

In order to maximise the response to the first questionnaire, personal mailing to individual trainees at their practices was attempted, rather than distribution via Course Organisers. Trainee mailing lists were requested from Regional Advisors in General Practice (except armed forces) in April 1992, with an explanation of the purpose of the study. Most provided names, practice addresses, and the date on which the trainees had started. However, in some regions the only available lists were of GP trainers, who may or may not have had a trainee currently in post.

Questionnaires were mailed to named trainees or 'to the trainee' of named trainers in June 1992, with one remailing to nonresponders. Mailing was undertaken specifically during these months in order to maximise the number of trainees who would be completing 
the questionnaire at the end of their training scheme.

Pilot studies of this questionnaire had been carried out at the 1990 National Trainee Conference and amongst small groups of trainees in 1992. Validity was judged by comparing responses elicited by self administered questionnaire and by subsequent semistructured interview. The final version of the trainee questionnaire included enquiry about the availability and curriculum of local rheumatology teaching. This included Senior House Officer (SHO) posts, outpatient clinics, regional study days, local day release courses, and practice based tutorials. Further questions included items about acquisition of joint and soft tissue injection skills, and perceived confidence concerning both when and how to perform these procedures. Additional items assessed trainees' ratings of their confidence in regional musculoskeletal examination and in the management of specific conditions, perceived adequacy of rheumatology education, and preferred educational methods.

The trainer questionnaire was based on a restricted set of items adapted from the trainee schedule. A pilot study was carried out amongst a small group of trainers who were members of the Primary Care Rheumatology Society. It was shorter and did not enquire about the trainers' own knowledge and confidence. Enquiry was made about their rheumatological training and interests, but concentrated on their perception of the rheumatological training received by trainees locally, and the practical instruction they provided for their trainees in the surgery.

ANALYSIS

Skills and confidence were rated on Likert scales from 1 to 10; analysis was based on median scores and interquartile ranges. Where appropriate, non-parametric statistical tests were used. For most other questions, proportions were calculated.

\section{Results}

Replies were received from 1624 trainees, which represented $70 \%$ of the 2272 trainees known to be in a UK training practice in April 1992 (personal communication, Department of Health). A total of 2500 questionnaires had been mailed originally as it was not known whether all the trainers who were to be contacted had a current trainee in post or not. The results presented here represent the replies of the 1075 respondents whose trainee year would have finished within two months of their completion of the questionnaire.

There were 900 replies from trainers-a response of $33 \%$ to the 2700 questionnaires mailed. The total population mailed was greater than for the trainee sample because it included some trainers known not to have had a current trainee in post. Each individual reply was anonymous and therefore could not be paired with the relevant trainees' reply. The results analysed and presented below are therefore for 'all trainers who responded' and 'all trainees who responded and were near the end of their trainee year'.

\section{EDUCATION \\ Undergraduate}

Nine hundred and sixty three $(90 \%)$ of responding trainees recalled receiving specific rheumatology education at medical school. Trainees did not perceive this education as particularly relevant to general practice, giving it a median rating of $5(1=$ not relevant at all, $10=$ very relevant).

\section{Postgraduate}

One hundred and three trainees $(9 \cdot 6 \%$ of the responders) had worked in a rheumatology SHO post, and an additional $16 \%$ had attended rheumatology outpatient clinics. Four hundred and sixty one $(43 \%)$ had experienced rheumatology teaching on local day release courses, and $207(20 \%)$ on regional study days. Within their practice, most trainees recalled attending tutorials on rheumatological topics $(696,65 \%)$, comprising a median of two hours per year. These experiences were broadly similar to the trainers' perception as to the amount of education provided for trainees.

In comparison, 251 of the trainers $(28 \%)$ recalled specific postgraduate rheumatology education before they had entered general practice; $637(72 \%)$ had attended courses or meetings on rheumatological topics since becoming a trainer.

Trainees who received tutorials in their practices recalled that the curriculum frequently included back pain, but that other common conditions were less frequently considered, particularly osteoporosis, management of musculoskeletal disability, and locomotor disorders in childhood (table 1).

The most frequent teacher of soft tissue injection reported by the trainees was the trainer, although $22 \%$ of them claimed to have been self taught (table 2). Instruction in joint injection was just as likely to have been by the trainer, an orthopaedic surgeon, or a rheumatologist. In the management of shoulder pain, the predominant teacher was an orthopaedic surgeon, although self instruction was reported almost as frequently. Table 3 compares this experience of the trainees with the account given by the trainers of the instruction they would expect to provide in the surgery.

Table 1 Tutorial topics reported by the trainees

\begin{tabular}{ll}
\hline Topic & $\begin{array}{l}\text { Trainees reporting topic } \\
\text { No (\%) }\end{array}$ \\
\hline Back pain & $563(52 \cdot 4)$ \\
Rheumatoid arthritis & $310(28 \cdot 8)$ \\
Soft tissue disorders & $282(26 \cdot 2)$ \\
Osteoarthritis & $280(26 \cdot 1)$ \\
Gout & $277(25 \cdot 8)$ \\
Osteoporosis & $235(21 \cdot 9)$ \\
Sports injuries & $223(20 \cdot 1)$ \\
Musculoskeletal disability & $147(13 \cdot 7)$ \\
Childhood locomotor disorders & $91(8 \cdot 5)$ \\
\hline
\end{tabular}

A total of 696 trainees $(65 \%)$ reported having a tutorial on any musculoskeletal topic. 
Table 2 Source of teaching reported by trainees who have conducted a joint or soft tissue injection and by all trainees with respect to the examination and treatment of shoulder pain

\begin{tabular}{llll}
\hline Who taught? & \multicolumn{2}{l}{ Area of teaching } & \\
\cline { 2 - 4 } & $\begin{array}{l}\text { foint injection } \\
(n=945) \\
\text { No }(\%)\end{array}$ & $\begin{array}{l}\text { Soft tissue injection } \\
(n=659) \\
\text { No }(\%)\end{array}$ & $\begin{array}{l}\text { Examine and treat } \\
\text { shoulder pain } \\
(n=1075) \\
\text { No }(\%)\end{array}$ \\
\hline Trainer & $255(27)$ & $319(48)$ & $276(26)$ \\
Self taught & $152(16)$ & $146(22)$ & $335(31)$ \\
Rheumatologist & $272(29)$ & $195(30)$ & $276(26)$ \\
Orthopaedic surgeon & $289(31)$ & $148(22)$ & $373(35)$ \\
Physician & $135(14)$ & $40(6)$ & $60(6)$ \\
\hline
\end{tabular}

« Some trainees indicated more than one source of teaching, hence percentages add up to more than 100 .

\section{TRAINEE SKILLS}

\section{Regional musculoskeletal examination}

Trainees' perceived self confidence at regional musculoskeletal examination was generally high, with median ratings of 8 for examination of the back, hip, and knee, 7 for the shoulder, and 6 for the foot. When confidence scores for examination at all these sites were pooled, no difference in median rating was observed between those trainees who had undertaken a rheumatology SHO post and those who had not.

\section{Acquisition of injection skills}

Most trainees (84\%) had injected or aspirated the knee, and those who had not were unlikely to have injected any other joint. Acquisition of shoulder injection skills was much less common, only $39 \%$ of the trainees having ever performed subacromial, and $34 \%$ glenohumeral injection.

Table 3 Experience of trainees giving soft tissue and joint injections: comparison with trainers' reported teaching

\begin{tabular}{|c|c|c|c|c|}
\hline \multirow[t]{2}{*}{ Injection site } & \multicolumn{2}{|c|}{$\begin{array}{l}\text { Trainees }(n=1075) \\
\text { (give injection) }\end{array}$} & \multicolumn{2}{|c|}{$\begin{array}{l}\text { Trainers }(n=900) \\
\text { (teach injection) }\end{array}$} \\
\hline & No $(\%)^{\star}$ & Rank & No $(\%)^{\star}$ & Rank \\
\hline Tennis elbow & $596(56)$ & 2 & $810(94)$ & 1 \\
\hline Golfer's elbow & $236(23)$ & 8 & $700(82)$ & 2 \\
\hline De Quervain's tenosynovitis & $123(12)$ & 10 & $388(46)$ & 9 \\
\hline Bicipital tendinitis & $142(14)$ & 9 & $436(52)$ & 8 \\
\hline Plantar fasciitis & $277(27)$ & 6 & $676(79)$ & 3 \\
\hline \multicolumn{5}{|l|}{ Shoulder } \\
\hline Glenohumeral joint & $416(39)$ & 3 & $548(64)$ & 6 \\
\hline Subacromial joint & $361(34)$ & 4 & $550(65)$ & 5 \\
\hline Acromioclavicular joint & $251(24)$ & 7 & $464(55)$ & 7 \\
\hline Knee joint & $897(84)$ & 1 & $614(72)$ & 4 \\
\hline Elbow joint & $292(28)$ & 5 & $310(37)$ & 10 \\
\hline
\end{tabular}

${ }^{\star}$ Calculated after excluding some spoiled answers.

Table 4 Trainees' perceived confidence at knowing when to inject (When) and at performing injection (How), according to whether they have ever performed the procedures or not

\begin{tabular}{|c|c|c|c|c|c|c|}
\hline \multirow[t]{3}{*}{ Injection site } & \multicolumn{3}{|c|}{ Ever injected } & \multicolumn{3}{|c|}{ Never injected } \\
\hline & \multirow[t]{2}{*}{ No (\%) } & \multicolumn{2}{|c|}{ Confidence score $†$} & \multirow[t]{2}{*}{ No (\%) } & \multicolumn{2}{|c|}{ Confidence score } \\
\hline & & When & How & & When & How \\
\hline \multicolumn{7}{|l|}{ Joint injection } \\
\hline Glenohumeral & $416(39)$ & $7(6-8)$ & $7(6-8)$ & $644(61)$ & $2(1-4)$ & $1(1-3)$ \\
\hline Subacromial & $361(34)$ & $7(6-8)$ & $7(6-8)$ & $699(66)$ & $2(1-4)$ & $1(1-4)$ \\
\hline Acromioclavicular & $251(24)$ & $7(5-8)$ & $7(5-8)$ & $803(76)$ & $2(1-5)$ & $2(1-4)$ \\
\hline Knee & $897(84)$ & $7(5-8)$ & $8(6-9)$ & $173(16)$ & $2(1-4)$ & $1(1-3)$ \\
\hline Elbow & $292(28)$ & $7(6-8)$ & $7(5-8)$ & $764(72)$ & $2(1-5)$ & $1(1-4)$ \\
\hline \multicolumn{7}{|l|}{ Soft tissue injection } \\
\hline Tennis elbow & $596(56)$ & $8(7-9)$ & $8(7-9)$ & $472(44)$ & $5(3-7)$ & $2(1-5)$ \\
\hline Golfer's elbow & $236(23)$ & $8(7-9)$ & $8(7-9)$ & $792(77)$ & $5(2-7)$ & $3(1-5)$ \\
\hline De Quervain's tenosynovitis & $123(12)$ & $7(6-8)$ & $7(5-8)$ & $898(88)$ & $2(1-5)$ & $1(1-3)$ \\
\hline Bicipital tendinitis & $142(14)$ & $5(3-7)$ & $5(2-7)$ & $883(86)$ & $3(1-5)$ & $1(1-4)$ \\
\hline Plantar fasciitis & 277 (27) & $8(7-8)$ & $8(7-9)$ & $763(73)$ & $3(1-5)$ & $1(1-4)$ \\
\hline
\end{tabular}

†Confidence ratings based on a scale of 1 (not confident) to 10 (very confident). Values are median (interquartile range).
Tennis elbow was the most frequently reported soft tissue injection (56\%), fewer trainees ever having injected the plantar fascia $(26 \%)$ or a golfer's elbow $(23 \%)$.

Table 4 shows the trainees' rating of their confidence at knowing when to inject and at injecting, for different sites and according to their reported experience. At any one site the confidence scores were clearly lower in those who had never injected compared with those who had.

Pooled scores of injection confidence at both joint and soft tissue sites were higher for those trainees who had undertaken a rheumatology SHO post (difference in pooled median scores were 14 for joint sites and 5 for soft tissue sites). Of the trainees who had not undertaken an SHO post, $177(19 \%)$ reported absolute 'no confidence' at performing any soft tissue injections (scores of 1 out of 10 at each site), compared with seven trainees $(7 \%)$ who had held an SHO post. There were similar differences for pooled scores of confidence at knowing when to inject.

\section{Management strategies}

The ratings of trainees' perceived confidence at managing specified conditions were generally high, with median scores of 8 for back pain and gout, 7 for osteoarthritis, 6 for osteoporosis, soft tissue disorders, sports injuries, diagnosing inflammatory arthropathies and second line monitoring, and 5 for childhood locomotor disorders. This compares with confidence ratings of 8 and 9 for the management of hypertension and asthma, respectively. The median ratings for each topic showed little difference between those who reported having a tutorial on the subject and those who had not. The pooled management confidence scores did not vary according to whether trainees had held a rheumatology SHO post or not.

\section{Educational methods}

Preferred educational methods were an SHO post, outpatient clinics, and tutorials or small group teaching, with distance learning being the least popular.

Overall, trainees perceived the amount of rheumatology education during their vocational training to be inadequate, with a median response of 4 ( $1=$ totally inadequate; $10=$ completely adequate).

\section{Discussion}

This was the first comprehensive national evaluation of rheumatology education and outcome during vocational training. Response to the trainees' questionnaire was satisfactory and the results are unlikely to misrepresent the general experience of trainees at the end of their year in training practices.

Although most trainees had received specific rheumatology undergraduate education, this was regarded as being of little relevance to general practice. However, the constraints on 
an already overcrowded medical school curriculum dictate that the amount of time devoted to rheumatology is unlikely to expand significantly in the near future. A restructuring of the undergraduate curriculum to allow more emphasis on the basic scientific principles relevant to common conditions has recently been advocated. ${ }^{13}$

One of the best opportunities to enhance rheumatology education is during vocational training, and positive attitudes developed towards the specialty at this stage are likely to continue. $^{14}$

There are conflicting views as to the value of including a rheumatology SHO post in training schemes. Currently, such posts are undertaken by fewer than $10 \%$ of trainees and, as expected, we have shown here that they lead to greater acquisition of injection skills, and that their perceived educational value is high. A greater perceived confidence at musculoskeletal examination was not demonstrated for trainees who had held these posts, probably because this was generally high amongst all trainees. However, such posts are limited in number and, in view of proposals to reduce the total time spent in SHO posts from 24 to 18 months, the availability of this type of training seems unlikely to increase. We did not specifically enquire about other SHO posts in which rheumatological skills might have been acquired, such as orthopaedics, trauma, and pain clinics.

It will be necessary to place greater emphasis on the development of community based teaching resources. Local release schemes, which run for an average 20 to 30 half days per year, are the ideal setting for small group rheumatology teaching, and yet this had been experienced by only $42 \%$ of trainees in our sample. Whilst there may be an adequate potential teaching resource from local rheumatologists, the problem appears to be poor availability of organised teaching. The proportion who reported a rheumatological component to local teaching was very similar among the trainees and the trainers, suggesting that this is a valid estimate of what is happening currently.

It is known from an earlier study that more than $90 \%$ of trainees receive tutorials from their trainer. ${ }^{12}$ In this study, $63 \%$ of trainees reported tutorials with any rheumatology component and these occupied a median of two hours per year. This suggests a low priority afforded to rheumatology compared with the known average total teaching of four hours per week, and the recommended seven hours per week. ${ }^{12}{ }^{15}$ Assuming 40 weeks of teaching per year, and thus a recommended 280 hours per year, some 28 teaching hours per year focused on musculoskeletal problems might be reasonable, based on the contribution of these conditions to primary care workload.

The acquisition of injection skills, though not necessarily the most important outcome of training, is a useful and easily measured endpoint. The high level of acquisition of knee injection skills reported by the trainees may be indicative of experience gained with joint aspiration in Accident and Emergency units. By comparison, the level of experience in shoulder injection was poor, despite the prevalence of shoulder disorders in the community and their associated morbidity. It should be noted in this respect that about $30 \%$ of trainees reported being predominantly 'self taught' in the management of shoulder pain; this may equate to skills which have not been properly acquired. Similarly, it might be expected that all trainees would be able to inject tennis elbow and plantar fascia at the end of their trainee year. Sixteen percent of trainees reported being 'self-taught' in joint injectionperhaps not to be unexpected, given the availability of promotional literature describing how to inject joints.

The trainers are undoubtedly a major teaching resource for such practical skills, but tutorials and personal teaching from the GP trainers can be encouraged only if the trainers themselves feel confident and experienced in dealing with musculoskeletal problems. It is here that the trainers' questionnaire is instructive. The response rate to this was poor, and the results must be interpreted with great caution. It is possible, even likely, that those who replied were more likely to be enthusiastic and experienced in their teaching of rheumatological skills. This would explain the high proportion who reported that they teach injection skills to their trainees, as the number of trainers who had previous rheumatology experience was no greater than the number of trainees who had worked in hospital rheumatology. One interpretation of the low response rate might be that a considerable number of trainers do not have the interest, skills or confidence in managing musculoskeletal problems and in teaching injection methods, or do not feel that such skills are important; this would reflect the picture drawn from the trainees' survey. Alternatively, the trainers who responded may represent the broad perceptions of the majority of trainers; in this case, these perceptions differ in being more optimistic than those of the trainees.

Another factor to be considered is that, although the trainer is willing to instruct, the opportunity may not arise. De Quervain's tenosynovitis, for example, might be too unusual in practice to rely on the GP's surgery as a suitable setting for acquiring technical skills in injection. The relative frequency with which tennis elbow was cited reflects this-it represents a well characterised, relatively common syndrome in practice. However, the differences between trainers' and trainees' accounts of what could be taught and what had been taught with respect to soft tissue problems of the shoulders, elbows and feet suggest that there is a real gap between intention and practice in this field of supervision.

In conclusion, despite the introduction of compulsory vocational training, rheumatology education and skill acquisition among GP trainees appear inadequate. It is necessary to place greater emphasis on rheumatology within the current vocational training and continuing 
medical education framework at regional and practice level, including debate about a core curriculum and about the rheumatological skills necessary for general practice.

This study was supported by an Arthritis and Rheumatism Council Education Project Grant (ref L005-6). Thanks are due to the Regional Advisors, the trainers and trainees who cooperated with the study and to Drs J S Coppock, G R Struthers, Gerated with the study and to Drs J S Coppock, G R Struthers, Ms Helen Livesley, and the Primary Care Rheumatology Society Steering Committee for advice and support. We are also grateful to Theo Papageorgiou, Alex Gorton, Rita Boswell and Lesley Jordan of the ARC Unit for data presentation and entry.

1 Martin J, Meltzer H, Elliot D. The prevalence of disability among adults. London: Office of Population Census and Surveys, 1988 .

2 Billings R A, Mole K F. Rheumatology in general practice: a survey in world rheumatism year. $f R$ Coll Gen Pract a survey in world

3 Fry J. Common diseases, their nature, incidence and care, 4th edn. Lancaster: MTP press, 1985; 239-42.

4 Wright V. The epidemiology of disability. $\mathcal{F} R$ Coll Physicians Lond 1982; 16: 178-83.
5 Griffin G A. Continuing education in rheumatology. $\mathcal{f} R$ Soc Med 1982; 75: 931-2.

6 Badley E M, Lee J. The consultant's role in continuing medical education of general practitioners: the case of rheumatology. BMF 1987; 294: 100-3.

7 Bamji A N. Rheumatology education: can you hear at the back? Rheumatology in Practice 1988; June: 5-6.

8 Dawes P T, Shadforth M F, Hothersall T E, McGuiness B. Primary care-the educational need. Br $f$ Rheumatol 1990; 29: 401.

9 Wright V, Harvey A. Rheumatology education in the late 20th century. Br f Rheumatol 1989; 28: 95-7.

10 Doherty M, Abawi J, Pattrick M. Audit of medical inpatient examinations: a cry from the joint. $\mathcal{F} R$ Coll Physicians Lond 1990; 24: 115-8.

11 Jones A, Maddison P, Doherty M. Teaching rheumatology to medical students: current practice and future aims. f R Coll Physicians Lond 1992; 26: 41-3.

12 Crawley H S, Levin J B. Training for general practice: a national study. $B M \mathcal{F} 1990 ; 300: 911-5$.

13 Jones A, Doherty $M$. 'The time has come the walrus said.' Ann Rheum Dis 1992; 51: 434-5.

14 Hull S A. Rheumatology education for general practice. Ann Rheum Dis 1991; 50: 449-52.

15 Joint committee on postgraduate training of general practice. Recommendations to regions for the establishment of criteria for the approval and reapproval of trainers in general practice. London: Joint Committee on Postgraduate Training in General Practice, 1985 